\title{
Traversing organisational cultures: Building student capacity to lead conversations about child protection policy reform
}

\begin{tabular}{|c|c|}
\hline \multicolumn{2}{|c|}{ School of Social and Policy Studies, Flinders University } \\
\hline Article history & The Australian child protection system is part of a broader \\
\hline $\begin{array}{l}\text { Received: } \\
01.03 .2015\end{array}$ & $\begin{array}{l}\text { complex, fragmented and multi-level approach to welfare } \\
\text { governance. In } 2009 \text {, with a key strategy being to stimulate 'joined- }\end{array}$ \\
\hline $\begin{array}{l}\text { Received in revised form: } \\
20.06 .2015\end{array}$ & $\begin{array}{l}\text { up thinking', Australia launched its first national child protection } \\
\text { framework. The policy mantra : 'Protecting Children is Everyone's }\end{array}$ \\
\hline $\begin{array}{l}\text { Accepted: } \\
23.06 .2015\end{array}$ & $\begin{array}{l}\text { Business' (COAG 2009) advocated the sharing of responsibility for } \\
\text { child protection across organisational entities, service sectors, } \\
\text { communities and families. Applied action learning with } 18\end{array}$ \\
\hline Key words: & Australian social work students is discussed as a case study of a \\
\hline $\begin{array}{l}\text { Participatory education, adult } \\
\text { learning, child protection, } \\
\text { policy reform, diffusions of } \\
\text { innovation }\end{array}$ & $\begin{array}{l}\text { participatory education model aimed at liberating student thinking } \\
\text { about child protection and at building their capacity to lead } \\
\text { conversations about the policy reforms at welfare agencies where } \\
\text { they were undertaking a field practicum. Students' conversations } \\
\text { helped to share the notion that Protecting Children is Everyone's } \\
\text { Business (COAG 2009) and thereby contributed to reform } \\
\text { strategies for more 'joined-up thinking' across organisational } \\
\text { entities. Students challenged, observed, shared and analyzed their } \\
\text { own thinking, competing agency philosophies and divergent } \\
\text { organizational cultures that inhibited the sharing of responsibility } \\
\text { for child protection. Student and teacher reflections indicated high } \\
\text { levels of motivation for learning when compared to traditional } \\
\text { teaching models previously employed. This was due to student } \\
\text { empowerment that respected their knowledge and experience, } \\
\text { shared control over the learning process, and participation in } \\
\text { learning that was liberating, meaningful and which produced } \\
\text { observable outcomes - personally, culturally and politically. }\end{array}$ \\
\hline
\end{tabular}

\section{Introduction}

This paper reports on an educational approach used with a cohort of 18 Australian social work students. The students were learning about child protection practice and policy reform affecting the Australian welfare system. The model applied participatory education with adult learners and blended diffusion of innovations theory in its design. Combining these

\footnotetext{
*Correspondence: helen.mclaren@flinders.edu.au
} 
theories aimed to liberate social work students in their thinking and develop their capacity as social actors who could participate in processes of social transformation, in the classroom and outside in the world. This was particularly important for students' future social work in Australia's welfare system, which is under constant reform and where the freedom to innovate and work flexibly across organisations is often constrained by fragmentation, complexity and resistance to new ways of tackling entrenched problems.

Social workers are 'change agents' and an important facet of social work education is to empower students to lead change in ways that enable the liberation of others in their communities, workplaces and wider society. The need for an educational approach in which students actively participate in the liberation of others is obvious when viewing the global definition of social work:

Social work is a practice-based profession and an academic discipline that promotes social change and development, social cohesion, and the empowerment and liberation of people. Principles of social justice, human rights, collective responsibility and respect for diversities are central to social work. Underpinned by theories of social work, social sciences, humanities and indigenous knowledge, social work engages people and structures to address life challenges and enhance wellbeing (International Federation of Social Workers, 2014).

With these words in mind, it is not enough to simply teach social work students the principles of social justice, human rights and advocacy, child protection law, policy and practice principles, and so forth. Nor is it sufficient to only engage students in the liberation of their own minds. In becoming socially responsible and to be part of social transformative processes, Paulo Freire advocated for participatory education in which actors transform themselves and thereby build capacity to transform whole societies. He said:

Even when you individually feel yourself most free, if this feeling is not a social feeling, if you are not able to use your recent freedom to help others be free by transforming the totality of society, then you are exercising only an individualist attitude towards empowerment or freedom ... While individual empowerment, the feeling of being changed, is not enough concerning the transformation of the whole society, it is absolutely necessary for the process of social transformation (Shor \& Freire, 1987, pp. 109-110).

This paper is organized into three parts. The first section provides an overview of the contexts of complexity within which learning about child protection and its reforms were situated. This includes the (dis)organization of Australia's welfare system, the child protection reforms and changes to Australian social work education. In the second section, the systemic background and shifts towards 'joined-up thinking' in welfare practice, as it related to child protection, provided a framework for participatory education in which individual learning formed a basis for liberated thinking and participation in social transformation. The third part of the paper provides how diffusion of innovations theory offered a mechanism and rationale for students' active participation in spreading the notion that Protecting Children is Everyone's Business (COAG 2009). While participatory education helped free the mind in the classroom and empower students with skills for participating in social transformative processes outside, diffusion of innovations theory helped guide end-processes in ways that were more likely to sustain students' ongoing engagement in social transformative processes no matter where they end up working.

\section{Contexts of complexity and instability within which the learning took place}

Developing the knowledge and skills to enable working in complex, fragmented and constantly evolving multi-jurisdictional governance systems is difficult. One such system is 
Australia's mixed model of welfare, which is comprised of government, non-government, business and quasi-government bodies that have a diversity of organisational philosophies and haphazard operational and funding relationships (McLaren, Gibson, Arney, Scott, \& Brown, 2009). As well, policy, inter-organisational protocols and service provision is constantly evolving. Located within the welfare system is Australia's child protection system, which is 'fragmented ....with differences between states and territories, gaps and overlaps in service delivery, and inter-jurisdictional complications' (Higgins, 2011, p. 6). This complexity has made both child protection work and other forms of social work practice operationally challenging. Understanding the intricacies, nuances and conflicts between of policy, philosophy and practice across organisations and welfare service sectors is even more difficult for those who are still learning. Traditional pedagogic education models that prioritize imparting information from the teacher to the learner does not equip students with the necessary tools for navigating these complex spaces in which working with children and their families in Australia takes place. Nor does it develop capacity for challenging oppressive structures, which is the basis of social work.

While discourses have historically informed that child protection in Australia is the responsibility of statutory child protection agencies, statutory child protection work is a specialization that intervenes with only a very small quantity of vulnerable children and families. Over the last decade, increased demands on each of Australia's state and territory based child protection systems has meant that the child protection workforce only has time for the most complex of cases that are time consuming and difficult to manage (Haly, 2010; Mansell, Ota, Erasmus, \& Marks, 2011; McCallum, 2008; Munro, 2010). Pressures upon staff has resulted in child protection agencies "no longer being regarded as an employer of choice for human services professionals" (Haly, 2010, p. 128). Staff turnover and lack of employment desirability has affected the critical expertise in statutory agencies that is required for complex child protection work (Healy, Meagher, \& Cullin, 2009). Diminished expertise, increasing demand on statutory agencies and systemic failure has forced child and family interventions to be outsourced to third sector agencies; many comprising of lower cost and/or lower skilled providers. In the light of these issues, gaps in service delivery have widened and many more children and families are at risk of falling through the gaps. It is not surprising that radical reform to child protection policy and philosophies in Australia transpired.

In 2009, Australia launched its first national child protection reform agenda. Documented as a series of plans and indicators in the National Child Protection Framework for Protecting Australia's Children 2009-2020: Protecting Children is Everyone's Business (COAG 2009), the reforms sought to encourage state players and other stakeholders to support systemic change. In recognition of increasing demands and diminished expertise in statutory child protection systems, a key component of the reforms involved promoting 'joined-up' thinking and shared responsibility for children and families across communities, governments, nongovernment organisations and business. Adult focused welfare services, such as in the drug and alcohol, homelessness and mental health sectors (McDougall \& Gibson, 2014; Roche et al., 2014) were encouraged to incorporate a child and family sensitive approach within their service frameworks. In recognition that intervention expertise for working with children and families could be located outside of statutory services and in other welfare service sectors, reform strategies focused on fostering 'joined-up thinking' in the best interests of the child. The focus was on breaking down organisational and welfare service silos, increasing responsiveness of adult specific services towards children and families; building of collaborative partnerships across organisations and welfare service sectors; sharing 
information where children's wellbeing was of concern; and, establishing communities of practice according to local need. If this could be achieved, then any organisation may be viewed as potential access points for children and families at risk.

At about the same time, amendments were made to the Australian Association of Social Worker's Education and Accreditation Standards (the AASWEAS) (AASW 2010). Specific child protection content was required to be introduced into the curriculum of all Australian accredited social work degrees. This included three core 'strands' of learning: policy and sociological contexts of working with children and families; complexities of working with families and children in the light of differing practice contexts; and theoretical models for working effectively with families and children. Consistent with the reform agenda, the ASWEAS (AASW 2010) supported a "Commitment to child-sensitive practice" across adult's and children's services through "recognizing that unless there is sensitivity to children's needs, children and parenting responsibilities can be invisible in adult services" (AASW 2010, Guideline 1:1, p.11). While the focus of curriculum content in the ASWEAS (AASW 2010) was voluminous, there was little guidance on how to help student negotiate and work within complex systemic spaces affecting social work practice, wherever that may be.

The Australian Centre for Child Protection (the ACCP) undertook a series of projects relating to child protection education. Firstly, they mapped child protection content within all professionally accredited Australian social work degrees and drew associations between a lack of child protection related education and an incapacity of the social workers in the welfare sector to work effectively with children and families at risk (Zufferey, Scott, \& Gibson, 2009). Secondly, the ACCP examined socio-political conditions optimal for facilitating the diffusion of child and family intervention programs across Australia (McLaren et al., 2009). It was thought that if diffusion could be understood, then it was possible to stimulate the rate of uptake of promising child protection interventions, educational technologies and concepts, such as a 'think child, think family'(Scott, 2009) attitude. Having formerly worked on these projects as a researcher at the ACCP myself, they stimulated a change in my approach to the education of social workers. These projects also resulted in a series of workforce development initiatives at the ACCP aimed at increasing child and family sensitive practice across service sectors. Since then, Zufferey and Gibson (2012) have examined online curriculum statements relating to child protection education across all Australian social work degrees. They offered assumptions on whether social work education might be preparing graduates to respond more effectively to children, but this project was futile. Curriculum statements that dot-point proposed subject matter to be imparted on students offers nothing about the educational theories applied in teaching and learning, nor insight into the learning outcomes achieved by individuals undertaking social work education.

Australia's child protection system and the broader welfare system are under constant pressure to change. Empowering social work students as transformative individuals and knowledgeable actors, who can work in complex evolving systems while liberating the thinking and actions of others is an important consideration. But before this can be achieved, students need liberating from their own thinking about child protection and the discursively formed social constructions that could potentially inhibit their future social work.

\section{Towards a liberated thinking about shared responsibility for children}

Traditionally, university teaching and learning has involved the transmission of information in lectures, followed by a tutorial, with the teacher being in control of what 
information is imparted and students are passive recipients. These teacher-directed approaches worked well enough "in the days when university classes contained highly selected students" who were academically inclined and who were "virtually teaching themselves" (Biggs, 1999). However, social work students in Australia are culturally diverse (Cooper, 2007; Grace et al., 2013; Gursansky \& Le Sueur, 2012) and diversity of feelings, attitudes and subjective experiences color the perceptions of students when learning about value laden themes such as child abuse, protection and intervention. As well, diverse students have different learning styles, educational backgrounds, motivations for learning and perceived investments in learning outcomes. Engaging students with diverse motivations can be difficult. As well, culturally mixed classes full of variable views, strong feelings and rigid thinking can be problematic for teaching and learning if not theoretically informed.

Participatory education offered a dialectic appreciation of empowerment (Shor \& Freire, 1987) and, by incorporating understanding about how adult learners (Knowles, 1972, 1980), a liberating process drew students with different experiences, motivations and learning styles closer together. For Paulo Freire, empowerment commences when individuals share and listen to each other, have liberating dialogues that identify commonalities, finds new ways of looking at problems through similarity and difference, and together discover strategies to facilitate individual and collective change. Observing how opinion makers describe problems and articulate solutions, such as via the ASWEAS (AASW 2010), the National Framework (COAG 2009) and other literature, is a facet of the participatory education process. Such exploration helps illustrate possibilities for empowerment, liberation and social transformation to students.

As subjective actors yet to be liberated and empowered, the students explored the ASWEAS (AASW 2010), the National Framework (COAG 2009) and other child protection literature. They shared their own perceptions, co-created meanings, named problems, found solutions and engaged in deep-thinking that was synonymous with student ownership over their own learning. Participatory education offered a process where students were not objective recipients of information, but instead active players in using information in transformative ways. In complement to the transformative process, via the educational setting, Knowles $(1972,1980)$ provided that adults learn best when:

- they know the reasons for their learning;

- can draw on their own work and life experiences as platforms for learning;

- are involved in the design and evaluation of learning;

- when learning has immediate relevance to their work and life contexts, and is problem centred; and

- when focused on problems rather than content matter.

Assumptions of adult learners appreciated the work and life experiences of students. And the concept of Paulo Freire's empowerment did not mean that students were powerless prior to becoming empowered, but instead participatory education brought students in touch with their own subjectivity and creativity in ways that that did not constrain their learning. Participatory education with adult learners, therefore, promoted a culture of respect between the teacher and learner, and between learners. This culture of respect promoted individual and social responsibility, healthy relationships based on understanding of diversity, and fairness and social justice in the teaching and learning space. Empowerment of students enabled the modelling of a social action process in which students gained mastery over their thinking about child protection in the context of the group, society and their political environments. In being subjective actors that transformed the self, students developed higher order skills that 
would contribute to the liberation of others and the transformation of oppressive structures in the agencies in which they were on social work field practicum. Assumptions of adult learners (Knowled, 1972, 1980) complemented participatory education.

Educational literature on the way that adults learn (Knowles, 1972, 1980) provided that students needed to know reasons for their learning. While embodying an interactive process of exchange and change, students were guided to deconstruct the curriculum requirements of the ASWEAS (AASW 2010) and philosophies of the National Framework (COAG 2009) in the light of the teacher's and learners' own conceptions. This included reflection on the articulation of specific child protection attitudes, knowledge and skills deemed necessary for the development of responsiveness towards children across the Australia's complex and fragmented governance systems. Conversations allowed students to explore and share their own perspectives about child abuse and protection, family responsibility and the role of the State. Inviting students to share their thoughts and feelings, value differences and observations respected adult learning principles by starting with students' work and life as a basis for learning.

In respect to participatory education, individuals must first be helped to understand the discourses and structures from which they need liberating. Hence Students' analysis of the two documents, the ASWEAS (AASW 2010) and the National Framework (COAG 2009), engaged a processes that challenged students' thinking about what they already knew about child protection and how they felt about the concept that Protecting Children is Everyone's Business (COAG 2009). Gentle challenging was achieved via a hermeneutic attitude engaged by the teacher. Iterative recursive responding when students shared their thinking and perspectives was done so in ways that allowed the students to introspect, clarify and redefine their attitudes and feelings about child protection at deeper levels. As the teacher, I shared my own extensive employment experiences in each the health, child protection, education, justice, disability sectors of the Australian Government and used this to stimulate conversations with students. My modelling of a hermeneutic attitude eventuated in students replicating this skill, thereby developing their own skills for having future conversations about the child protection reforms inside and outside of the classroom.

These initial conversations opened up opportunities for students to share their future aspirations for child protection, the reforms, solutions for systemic problems, approaches to facilitate liberation and change, and the potential of benefits of Protecting Children is Everyone's Business (COAG 2009). This included:

Visions of worthwhile outcomes for children and families should the philosophy of Protecting Children is Everyone's Business (COAG 2009) achieve mainstream uptake;

Motivation for change in thinking about child protection responsibility among the students through reflection, challenging and liberation of thinking;

The exposure of fears and misconceptions about what constitutes child protection, including how any social worker can contribute to strengthening the protective environments of children;

A discussion about underlying drivers of stigma associated with child protection workers that are discursively created, reinforced by media and which source a level of resistance towards taking responsibility for child protection; and

Developing skills to have inquisitive conversations, challenge status quo and change individual and organisational behaviour.

Developing skills to have inquisitive conversations at the students' practicum agencies was 
further developed with the use of interactive role plays, ongoing conversations and by reflecting on these activities. While the content material of the ASWEAS (AASW 2010) was eventually achieved, the students' learning pathway meandered in accordance with the students' conversations, ongoing reflection and evaluation. Incrementally they negotiated the next directions for learning. This ongoing process enabled the educational approach to constantly be pitched at a level consistent with the student cohorts' existing knowledge, skills and abilities as they evolved. The promotion of student co-ownership over learning, their interaction and the application of participatory education contributed to a sound development of skills for working with risk, complexity, uncertainty and ambiguity (Parton, 1998, 2008, 2011), as well as to be active participants in social transformation. These are the contextual skills for working in social work - even more so, child protection work.

The participatory education approach located the students as central and, although the teacher provided initial guidelines to students and contributed background experiences and knowledge, the teaching role was primarily that of a guide and mentor. The design specifically aimed to acknowledge and draw from the expertise of students, enabling spaces to share this with peers, and deciding on new knowledge that would build upon the students' already established foundations. Where gaps in knowledge were identified it was important for students to design ways of seeking evidence, developing new knowledge, evaluating their growth resulting from engagement in learning and with relevance to the world around them. These processes were synonymous with range of authors on educational technology, such as those who seek to promote depth of learning through investigation, interaction and participation (for example, see: Boyer, 1990; Dewey, 2007; Knowles, 1972, 1980; Kolb, 2014; Shor \& Freire, 1987) (for example: Boyer, 1990; Dewey, 1997; Knowles, 1972, 1980; Kolb, 1983), while also making learning relevant, challenging and interesting.

With consideration of Knowles $(1972,1980)$ assumptions of adult learners, he suggested that adults learn more successfully when they are part of a learning community and have a stake in what is to be learned. In particular, he suggested that adult learners attached more significance to learning when it drew upon work, life and cultural experiences. And when learning satisfied students' own particular individual or professional needs, better learning outcomes were achieved. This is because students had a role in the planning, negotiation and contracting the educational tasks, and they were stakeholders in determining what they thought was necessary to achieve each of their own learning outcomes. For this reason, learning that took place in the classroom was integrated with their learning about child protection reforms outside of the classroom - at their practicum agencies. The conversations that students had in their learning communities inside the classroom, in which a hermeneutic attitude was modelled, involved deconstructing the child protection reform agenda (COAG 2009) and a reflective approach to understanding their visions, motivations, fears, conceptions and stigma associated with child and family sensitive work.

The educational processes that involved modelling a hermeneutic attitude was replicated in their conversations with others. Gaining mastery over their learning about child protection in the context of personal, social and political environments empowered the students with skills to facilitate interactive processes when conversing about child protection reforms at their field practicum agencies. It was possible, therefore, that students could free up thinking at these locations that were previously resistant to the notion that Protecting Children is Everyone's Business (COAG 2009). In so doing, this could lead to new approaches to practice that were more considerate towards the best interests of children and their families. A hermeneutic attitude in the students' conversations meant that they had the skills to apply in attempting to 
achieve social transformations at their practicum agencies.

Participatory education intended to empower students to free themselves and thereby "help others be free by transforming the totality of society" (Shor \& Freire, 1987, pp. 109-110). Adult learning principles offered understanding into how adults learn (Knowles, 1972, 1980). While both were invaluable for empowerment, liberation and learning, I wanted more than just a one-off transformative action to take place. Diffusion of innovations theory provided understanding how students could facilitate the spread of the notion that Protecting Children is Everyone's Business (COAG 2009). It also provided insight into how the students new skills in social transformation could be sustained.

\section{Sustaining liberated thinking necessary for process of social transformation}

Diffusion of innovations literature (Greenhalgh, Robert, Bate, MacFarlane, \& Kyriakidou, 2005; McLaren et al., 2009; McLaren \& Kenny, 2015; Rogers, 2003) offered useful understandings about the conditions that may facilitate spread, innovation uptake and increase the likelihood that the use of something new would be sustained; innovations being a new idea, concept, product, way of thinking, or action, etc. Rogers (2004) proposed that if conditions facilitating the spread of something new among a given group or social system could be understood, then it was possible to stimulate the uptake of innovation and its rate of spread. He articulated the diffusion of innovation process as a series of sequential stages: gaining knowledge of an innovation; being persuaded to consider its usefulness; making decisions about the innovation's utility that might lead to adoption; implementing the innovation, and; receiving confirmation that adoption was worthwhile. If the 'right' conditions existed, then successful diffusion consisting of mainstream uptake was more likely.

In regards to the teaching and learning framework, it was thought that the application of diffusion of innovations theory could be used to design a model in which social work students help diffuse the notion that Protecting Children is Everyone's Business (COAG 2009) via their practicum agencies. If student thinking was liberated from the constraints of discursive constructions informing that child protection in Australia was primarily the responsibility of statutory child protection agencies, then it could be possible for students spread alternative notions while also engaging in suitably informed child protection education. As the educator, I shared these thoughts with the students. Student and teacher reflections indicated that conversations at practicum agencies did facilitate liberated thinking that contributed to the uptake of the notion that Protecting Children is Everyone's Business (COAG 2009) at students' his practicum agencies. But other government and research bodies were at the same time spreading the reform agenda via advocacy activities, practice guidance and workforce development initiatives (Higgins \& Katz, 2008; Lonne, Harries, \& Lantz, 2012). Students were part of spreading the reform, but the outcomes of their own participation in social transformation could not be isolated.

While as an educator I wanted students to be part of the child protection reform agenda, but admittedly this was to serve my own liberation and participation in processes of social transformation. I realized that diffusion of innovations theory offered much more to the educational process. Student involvement in participatory education could, in itself, serve to facilitate the use of Paulo Freire's lessons as a skill for individual liberation and social transformative action that could be sustained for longer-term use as social workers. Diffusion of innovations theory, therefore, balanced the challenge with participatory education - that is, 
participatory education was liberating and socially transformative, but diffusion of innovation theory contributed how sustained use of social transformative practice among social work students could be achieved.

As a multi-step flow process, the first few sequential stages of the diffusion of innovations process complemented participatory education with adult learners. For example: with participatory education students need to know from what they need liberating (Shor \& Freire, 1987); the first assumption of adult learners is that adults need to know a rationale for the focus of learning (Knowles, 1972, 1980); and diffusion of innovations theory starts with knowledge of the innovation (Rogers, 2003). During initial conversations I reminded students of the definition and purpose of social work to engage "people and structures to address life challenges and enhance wellbeing" (International Federation of Social Workers, 2014) and Paulo Freire's concern that individual freedom was not enough, but that our purpose as social workers made it necessary to engage in "the process of social transformation" (Shor \& Freire, 1987, pp. 109-110). Secondly, participatory education located students as central and their empowerment drew from existing knowledge and experience. Assumption of adult learners supported that learning was best when adults used their own work and life experiences as foundations.

Diffusion of innovations theory proposed that, as individuals became more interested in something, that they are more likely to explore it (Rogers, 2003). In accordance with assumptions of adult learners, students were more interested when learning has immediate relevance to their work and life (Knowles, 1972, 1980). As well, adult learners are more motivated when involved in design and evaluation, which provides a sense of achievement (Knowles, 1972, 1980). Being able to observe changes at their agencies provided students this sense of achievement; therefore, motivation for learning. Finally, Rogers (2003) suggested that for an innovation to be sustained, such as a new way of liberating the mind, conversing or participation in social transformative action, that individuals need to be able to observe usefulness and relative advantage. This meant that students needed opportunities to evaluate and consider the outcomes of their new skills and participation in transformative processes to be able to sustain their use.

Rogers (2003) suggested that innovations need to offer some form of development or improvement to the existing alternatives. Therefore it was important for students to be able to consider new policy to practice concepts in the light of traditional understandings. When students were able to weigh up the relative advantage of conceptualizations of the child protection reform agenda, including that Protecting Children is Everyone's Business (COAG 2009), then it was more likely to increase students' motivation to interact with policy documents, learn about child protection and its reforms, and lead social transformative conversations. In being active players who might stimulate change at their field practicum agencies, diffusion of innovations theory offered a rationale for engendering child protection reform into the teaching model and for spreading its philosophies. Therefore, participatory learning helped stimulate transformation in the classroom and diffusion of innovation theory provided the teacher with a rationale for students as conduits to stimulate change outside. As well, diffusion of innovation provided the missing steps in the educational process that might lead to sustained student use of liberated thinking and skills used in social transformative processes.

Diffusion of innovations theory (Rogers 2003) offered that the observability of something new contributed to decisions on whether to adopt or reject them. Participatory education 
liberated students to imagine, reflect and weigh up the potential benefits of applying principles and strategies from within the National Framework (COAG 2009) to their social work practice. Knowles $(1972,1980)$ assumptions of adult learners offered that a sense of achievement may serve as a motivator for learning. While it was expected that some resistance to change might be experienced by students at their practicum agencies, nearly all students reported that agency workloads often prevented workers at their practicum agencies from keeping abreast of policy and practice trends. Conversations about the child protection reforms introduced liberating thinking that offered new ways to embrace social justice, human rights, collective responsibility and respect for diversities that are central to social work.

In reflecting on their participation in processes of social transformation at their social work practicum agencies, students reported that their conversations stimulated practice change. This included policy and practice developments aimed to foster child and family sensitive practice, assessment protocols that sought information about the wellbeing of service users' children, and child-friendly spaces at agencies. Reflective conversations with student peers exposed a sense of excitement, purpose and achievement among them. Students, upon seeing the outcomes of their conversations, were able to evaluate social transformations in the interests of child protection and make decisions on whether to sustain participation in social transformation. This suggested that diffusion of innovation of concepts, such that Protecting Children is Everyone's Business (COAG 2009), and skills for personal liberation and social transformation via the teaching and learning space was possible.

\section{Conclusion}

The thinking behind the educational approach described in this paper offers one strategy that challenged the way social work students understood and learned about child protection and its reforms. It empowered them as social actors who could lead conversations aimed at stimulating social transformation. In doing so the students learned and applied skills that engaged people, championed ideas and stimulated the thinking of others with a view to "address life challenges and enhance wellbeing" (International Federation of Social Workers, 2014). Underpin by diffusion of innovations, participatory education offered a potential to engage students in a political process beyond the traditional teaching and learning space; and engaged them in a process that sought to contribute to facilitating the spread ideas to do with the breath of child protection responsibility across welfare service sectors, liberation and social transformation. On the other hand, assumptions of adult learners offered a concept of the student as essentially self-directed, with the teacher there to encourage and nurture the conditions that enable learners to achieve their learning needs. Whether based on diffusion of innovations (Rogers, 2003), participatory education (Shor \& Freire, 1987) or assumptions of adult learners (Knowles, 1972, 1980), my role became that of strategic facilitator.

The aim of participatory education with adults and blending with diffusions of innovations theory fostered conditions in which the adoption of new ways of thinking and acting could take place; as well, to facilitate learning in ways that would motivate students in their approach to studying something new. Hence the endeavor was twofold - students acted as conduits for spreading new ideas about child protection via conversations aimed to challenge entrenched problems and staunch views. Students developed skills that would enable liberation from their thinking, be creative and contribute to tacking entrenched problems in Australia's complex, fragmented and constantly evolving multi-jurisdictional governance system. In undertaking this task, students' coincidentally developed knowledge in child protection in accordance with professional social work education requirements. 
Rogers (2003) suggested that complexity may increase or reduce the likelihood and rate of adoption. If new concepts are too challenging or complex, then perceived complexity could become an impediment to the adoption of new ways, new thinking, new principles, new social work technology, and so forth. However, applying educational technologies in ways that build upon students' existing foundations makes learning more meaningful and relevant. Conversations helped students make connections between their values, knowledge and skills and to develop understanding in accordance with required learning (Ramsden, 2003). In doing so, the level of complexity for the student cohort, as it related to child protection, diminished. Lower complexity translated to increased likelihood of adoption of new ideas and skills among students. These approaches taken in teaching and learning were critical to the adoption of new ideas, principles and/or technologies for later use in social work practice.

A positive and progressive change in student's views regarding the breadth of child protection focus and responsibility, as well as strategies for multi-sector child and family focused work was observed in the students' ongoing reflections and interactions. According to the students, their engagement in in co-determining the direction of their learning helped them to feel safe in expressing their own views and it offered an environment that respectfully challenged them. In doing so, students expressed greater confidence to deconstruct social policy, conceptualise applications to their social practice, and to lead conversations with others who might not necessarily see eye-to-eye with them. No matter where the students end up working, their conversations at practicum agencies regarding Protecting Children is Everyone's Business (COAG 2009) enabled the development of skills to challenge existing socio-political conventions informing messy practice in complex systems with entrenched problems.

At the time of their learning, students were undertaking social work field practicum at diverse agencies across Australia's welfare system. They were learning about child protection and leading inquisitive conversations about Australia's child protection reforms at their practicum agencies. Students respectfully challenged the governance, political systems and practice arrangements that were perceived as inhibiting 'joined-up thinking' in the best interests of children. While systemic change is slow and requires the release of whole societies from oppressive norms and societal structures, students were able to observe and reflect on the rippling effects of their conversations at their field practicums. This empowered them to work with individuals at these agencies and implement child and family sensitive considerations regardless of agency philosophy and organisational culture. While the social transformations observed could not be measured, from the students' reflections we knew that the contribution of students to both individual and social transformative process was significant. The observability of outcomes of students' participation in social action meant that uptake of new philosophies and capacity to lead conversations in ways that were influential would be longlasting.

\section{References}

Australian Association of Social Workers (AASW). (2010). Australian social work education and accreditation standards. Canberra: AASW.

Boyer, E. (1990). Scholarship reconsidered: priorities of the professoriate. Princeton: The Carnegie Foundation for the Advancement of Teaching.

Cooper, L. L. (2007). Backing Australia's future: teaching and learning in social work. Australian Social Work, 60(1), 94-106. 
Council of Australian Governments (COAG). (2009). Protecting children is everyone's business: National framework for protecting Australia's children 2009-2020.

Canberra: FaHCSIA.

Dewey, J. (2007). Experience and education: Simon and Schuster.

Grace, M., Townsend, R., Testa, D., Fox, J., O'Maley, P., Custance, J., \& Daddow, A. (2013). Student diversity as grass roots internationalisation in social work education.

Greenhalgh, T., Robert, G., Bate, P., MacFarlane, F., \& Kyriakidou, O. (2005). Diffusion of innovations in health service organizations: a systematic literature review. Oxford: Blackwell.

Gursansky, D., \& Le Sueur, E. (2012). Conceptualising field education in the twenty-first century: contradictions, challenges and opportunities. Social Work Education, 31(7), 914-931.

Haly, M. K. (2010). Neoliberalism and Child Protection: A Deadly Mix. Labour History: A Journal of Labour and Social History(98), 121-141.

Hare, I. (2004). Defining social work for the 21 century: The International Federation of Social Workers' revised definition of social work. International Social Work, 47(3), 407-424.

Healy, K., Meagher, G., \& Cullin, J. (2009). Retaining novices to become expert child protection practitioners: Creating career pathways in direct practice. British Journal of Social Work, 39(2), 299-317.

Higgins, D. (2011). Protecting children: Evolving systems. Family Matters, 89, 5-10.

Higgins, D., \& Katz, I. (2008). Enhancing service systems for protecting children. Family Matters(80), 43.

International Federation of Social Workers. (2014). Update on the refiew of the Global Definition of Social Work. Retrieved 26 February, 2015, from http://ifsw.org/getinvolved/global-definition-of-social-work

Knowles, M. (1972). Innovations in teaching styles and approaches based upon adult learning. Journal of Social Work Education, 8(2), 32-39.

Knowles, M. (1980). The modern practice of adult education: From pedagogy to andragogy. Englewood Cliffs: Cambridge.

Kolb, D. A. (2014). Experiential learning: Experience as the source of learning and development: FT Press.

Lonne, B., Harries, M., \& Lantz, S. (2012). Workforce development: A pathway to reforming child protection systems in Australia. British Journal of Social Work, bcs064.

Mansell, J., Ota, R., Erasmus, R., \& Marks, K. (2011). Reframing child protection: A response to a constant crisis of confidence in child protection. Children and Youth Services Review, 33(11), 2076-2086.

McCallum, D. (2008). Representing and intervening in child abuse law, statistics, community. Communication, Politics \& Culture, 41(1), 63-77.

McDougall, S., \& Gibson, C. (2014). Advancing the visibility of the child in adult and child and family services. Communities, Children and Families Australia, 8(1), 21-35.

McLaren, H. J., Gibson, C., Arney, F., Scott, D., \& Brown, L. (2009). Sowing the seeds of innovation: exploring the utility of diffusion of innovation theory. Paper presented at the The History and Future of Social Innovation Conference, 9-21 June, The Hawke Centre, Adelaide, ISBN 978-0-86803-827-8.

McLaren, H. J., \& Kenny, P. L. (2015). Motivating change from lecture-tutorial modes to less traditional forms of teaching. Australian Universities Review, 57(1), 26-33.

Munro, E. (2010). Learning to reduce risk in child protection. British Journal of Social Work, 40(4), 1135-1151. 
Roche, A. M., Trifonoff, A., White, M., Evans, K., Battams, S., Adams, V., \& Scarfe, A. (2014). From policy to implementation: Child and family sensitive practice in the alcohol and other drugs sector. Canberra: National Centree for Education and Training on Addiction, commissioned by the Australian National Council on Drugs.

Rogers, E. (2003). Diffusion of innovations (5th ed.). New York: Free Press.

Scott, D. (2009). 'Think Child, Think Family': How Adult Specialist Services Can Support Children at Risk of Abuse and Neglect.

Shor, I., \& Freire, P. (1987). What is the" dialogical method" of teaching? Journal of education, 11-31.

Zufferey, C., \& Gibson, C. (2012). Social Work Education and Children. Australian Social Work(ahead-of-print), 1-11.

Zufferey, C., Scott, D., \& Gibson, C. (2009). Making children visible in social work education. Australian Association for Social Work and Welfare Education. 